\title{
Terfezia claveryi Chatin’in besinsel içeriği, antioksidan ve antimikrobiyal aktivitesi
}

\section{Nutritional content, antioxidant and antimicrobial activity of Terfezia claveryi Chatin}

Şule INCi, Sevda KIRBAĞ

Fırat Üniversitesi Fen Fakültesi Biyoloji Bölümü, Elazığ, Türkiye

\section{Eser Bilgisi / Article Info}

Araştırma makalesi / Research article DOI: 10.17474/artvinofd.375460

Sorumlu yazar / Corresponding author Şule inCi

e-mail: sule.inci@hotmail.com

ORCID: 0000-0002-4022-5269

Geliş tarihi / Received

05.01.2018

Düzeltme tarihi / Received in revised form

21.09.2018

Elektronik erişim / Online available

11.10.2018

\section{Anahtar kelimeler:}

T. claveryi

Besinsel içerik

Antioksidant aktivite

DNA koruyucu aktivite

Antimikrobiyal etki

\section{Keywords:}

T. claveryi

Nutritional value

Antioxidant activity

DNA protective activity

Antimicrobial effect

\begin{abstract}
Özet
Bu çalışmada; Terfezia claveryi Chatin'nin besinsel içeriği, antioksidan ve antimikrobiyal aktivitelerinin belirlenmesi amaçlanmıştır. T. claveryi'de \% 89.59 kuru madde, $\% 0.04$ ham kül, $\% 0.03$ ham yağ, \% 15.31 ham protein, $\% 83.47$ organik madde, \% $399.98 \mathrm{kcal}$ enerji ve \% 10.40 nem saptanmıştır. Makro ve mikro element miktarları ise $52.5 \mathrm{mg} / \mathrm{kg} \mathrm{K}, 560 \mathrm{mg} / \mathrm{kg} \mathrm{Na}, 2.76 \mathrm{mg} / \mathrm{kg} \mathrm{Fe}, 0.37 \mathrm{mg} / \mathrm{kg} \mathrm{Zn}, 0.58 \mathrm{mg} / \mathrm{kg}$ Ca olarak belirlenmiştir. T. claveryi'nin total antioksidan seviyesi $1.18 \mu \mathrm{mol} / \mathrm{l}$ ve total oksidan seviyesi $3.45 \mu \mathrm{mol} /$ I olarak tespit edilmiştir. Ayrıca; mantarın DNA koruyucu aktivitesi pBR322 plazmit DNA'sı kullanılarak belirlenmeye çalışımış ve DNA koruyucu aktivitesinin olmadığı tespit edilmiştir. $T$. claveryi'nin antimikrobiyal çalışması sonucunda mikroorganizmalara düşük konsantrasyonlarda bile etki gösterdiği görülmüştür. Özellikle, P.aeruginosa'ya karşı en yüksek antimikrobiyal etki gösterdiği belirlenmiştir. Sonuç olarak $T$. claveryi'nin besin içerikleri bakımından zengin olması, element düzeylerinin toksik etki taşımadığı ve tıbbi açıdan önemli bir besin kaynağı olduğu belirlenmiştir.
\end{abstract}

\begin{abstract}
In study; It was aimed to determine the nutritional content, antioxidant and antimicrobial activities of Terfezia claveryi Chatin. T. claveryi contained $89.59 \%$ dry matter, $0.04 \%$ crude ash, $0.03 \%$ crude oil, $15.31 \%$ crude protein, $83.47 \%$ organic matter, $399.98 \% \mathrm{kcal}$ energy and $10.40 \%$ moisture. Macro and micro element contents were determined as $52.5 \mathrm{mg} / \mathrm{kg} \mathrm{K}, 560 \mathrm{mg} / \mathrm{kg} \mathrm{Na}, 2.76 \mathrm{mg} / \mathrm{kg} \mathrm{Fe}, 0.37 \mathrm{mg} / \mathrm{kg}$ $\mathrm{Zn}$ and $0.58 \mathrm{mg} / \mathrm{kg} \mathrm{Ca}$. The total antioxidant level of $T$. claveryi was $1.18 \mu \mathrm{mol} / \mathrm{l}$ and the total oxidant level was $3.45 \mu \mathrm{mol} / \mathrm{l}$. Also, the DNA protective activity of the $T$. claveryi has been identified using pBR322 plasmid DNA, and DNA protective activity was determined to be absent. As a result of the antimicrobial study of $T$. claveryi, microorganisms have been shown to be effective even at low concentrations. In particular, it has been shown to exhibit the highest antimicrobial activity against $P$. aeruginosa. In conclusion, it is determined that $T$. claveryi is rich in nutrient content, element levels are not toxic and it is a medically important food source.
\end{abstract}

\section{GiRiş}

Makrofunguslar; insanoğlu tarafından, düşük yağ ve kalori değerleri ile doymamış yağ asidi, zengin mineral element, vitamin, amino asit, karbonhidrat ve protein gibi besleyici değerleri ile düzenli diyetin bir parçası (Breene 1990; Mattila ve ark. 2000), aroma içerikleri, lezzetleri ve aşçılıkla ilgili özelliklerinden dolayı besin kaynağı olarak (Misaki ve Kakuta 1995) ve tıbbi ile tedavi edici özellikleri ile binlerce yıldır farkı amaçlar için kullanıldığı görülmektedir (Gunde-Cimerman 1999; Sanmee ve ark. 2003).

Çöl ve Orman trüfleri; Ascomycotina'ya ait olup, toprak altında ve yüzeye yakın yetişen, yenen, lezzetli aromaya içeriğine sahip doğal besin kaynaklarıdır. Orman (Tuber) ve çöl (Picoa, Terfezia ve Tirmania) türleri, Pezizales
J.Schrot' in farklı bir taksonunda yer almaktadır (Kagan Zur ve ark. 2014).

Trüf mantar türleri; Antartika kıtası dışında dünyanın farklı bölgelerinde yayılış göstermektedir. Çöl trüfleri farklı özelliklerdeki toprak yapısının bulunduğu habitatlarda Cistaceae ait bitkilerin kökleriyle mikoriz olarak hayat döngüsünü tamamlamaktadır (Kagan Zur ve ark. 2014). T. claveryi çöl mantarı olarak bilinmekte ve dünyada yenilebilir mantar türleri arasında yer almaktadır. Ilkbahar aylarında Cistaceae'ye ait olan Helianthemum türlerinin yaygın olarak bulunduğu kumlu, killi, taşlık özellikli topraklarda gelişim göstermekte ve toprağı çatlatabildiğinden kolayca tespit edilebilmektedir (Gutiérrez ve ark. 2003; Loizides ve ark. 2012). 
Kurak yarı kurak ve çöl türf mantar türleri (Terfezia, Picoa, Tirmania, Tuber vb.), Ülkemizin farklı yerlerinde doğal olarak yetişmekte, besin olarak tüketilmekte, ekolojik ve tıbbi önemleri bilinmektedir (Aydın 2009; Castellano ve Türkoğlu 2011; Akyüz ve ark. 2012; Akyüz 2013; Dogan ve ark. 2013; Türkoğlu ve Castellano 2014; Akyüz ve ark. 2015ab; Kıvrak 2015; Türkoğlu ve ark. 2015; Akyüz ve ark. 2016; Doğan ve Kurt 2016; Elliott ve ark. 2016; Sevindik ve ark. 2018). Ülkemizde de doğal olarak yetişen ve besin olarak aranılan bir tür olan T. claveryi, özellikle Adana, Kastamonu, Denizli, Şanlıurfa, Konya, Aksaray, Diyarbakır, Karaman, Yozgat, Elazığ vb. yerlerde doğal olarak yayılış göstermektedir (Bekçi ve ark. 2011; Şahin 2012; Türkoğlu ve ark. 2015; Doğan ve Kurt 2016).

Trüf mantar türlerinin az miktarda bulunmaları, doğaya bağımlı olması, kültür çalışmalarının çok zor ve uzun yıllar alması, lezzet, aroma ve kokusunun gurmeler tarafından cezbedici bulunmaları nedeniyle, zengin kıtalarda üst gelir grubu tarafından tercih edilmektedir. Dünyanın farklı yerlerinde trüf mantar türlerinin ekolojik önemleri ile birlikte, ekonomik değerlerinden dolayl; medikal, besinsel, etnomikolojik ve ticari potansiyelleri ile kültür çalışmalarına yönelik araştırmalar son yıllarda hız kazanmıştır (Kagan Zur ve ark. 2014).

Bu çalışmada; Baskil-Elazığ çevresinde doğal olarak yetişen $T$. claveryi'in besinsel içerikleri (nem, kuru madde, ham kül, ham protein, ham yağ, protein, karbonhidrat ve enerji), ile tıbbi etkilerinin (toplam oksidasyon ve antioksidant düzeyi ile DNA koruyucu aktivitesi) belirlenmesi amaçlanmıştır.

\section{MATERYAL ve YÖNTEM}

\section{Mantar Örneğinin Eldesi}

T. claveryi mantar örnekleri, 2014-2015 yılları arasında Elazığ-Baskil ilçesi ve çevrelerinde ilkbahar yağışları ile birlikte Mart - Mayıs aylarında araziden toplanmıştır. Örnekler kurutulup değirmende toz haline getirildikten sonra soxhlet cihazında metanol ekstraksiyonu yapılmıştır. Liyofilize edilerek tamamen kurutulan mantar örneği analiz edilene kadar $+4{ }^{\circ} C^{\prime}$ de saklanmıştır.

\section{Besinsel İçeriklerin Belirlenmesi}

Mantar örneğinin ham besin madde (kuru madde, nem, organik madde, ham kül, ham protein, ham yağ) bileşimleri ve element (mikro-makro element) düzeyleri literatürlerdeki (AOAC 1990) analiz metotlarına göre belirlenmiştir.

\section{Element Düzeyi}

Mantar örnekleri oda sıcaklığında $\left(25^{\circ} \mathrm{C}\right)$ yaklaşık 2 hafta süreyle kurutulduktan sonra, öğütülmüş ve $105^{\circ} \mathrm{C}^{\prime}$ de 24 saat süreyle etüvde bekletilmiştir. Belli miktarda (1 g) alınan örnek erlene koyulup üzerine, nitrik asit $\left(\mathrm{HNO}_{3}\right)$, sülfirik asit $\left(\mathrm{H}_{2} \mathrm{SO}_{4}\right)$ ve hidrojenperoksit $\left(\mathrm{H}_{2} \mathrm{O}_{2}\right)(10: 1: 1 \mathrm{ml})$ ilave edilmiştir. Daha sonra numune Isıtılarak, beyaz berrak çözelti oluşuncaya kadar kaynatılmıştır. Soğuyan numune süzülerek $50 \mathrm{ml}$ saf suya tamamlanmıştır. Örneklerde; Fe ve $\mathrm{Zn}$ gibi eser element içerikleri atomik absorbsiyon spektrofotometresi ile $\mathrm{K}, \mathrm{Ca}$ ve $\mathrm{Na}$ ise atomik emisyon spektrofotometresi ile tayin edilmiştir (AOAC 1990).

\section{Tıbbi Etkilerin Belirlenmesi}

\section{Antioksidan aktivite}

Toplam oksidan seviye (TOS)

Örneğin total antioksidan seviyesi, Rel Assay DiagnocticsTOS Assay Kit kullanılarak ölçüldü. Oksidan varlığında ferröz iyon şelatör kompleksini ferrik iyona oksitler. Reaksiyon ortamında oksidanların bulunmasına bağlı olarak oksidasyon reaksiyon yoğunluğu artış gösterir. Ferrik iyon asidik ortamda renkli bir kompleks oluşturur. Spektrofotometrik olarak ölçülebilen renk yoğunluğu, örnekte bulunan toplam oksidan molekül miktarı ile ilgilidir. Sonuçlar hidrojen peroksit ile kalibre edilerek $\mu \mathrm{mol} \mathrm{H}_{2} \mathrm{O}_{2}$ equiv./It olarak ifade edildi (Erel 2005).

\section{Toplam antioksidan seviye (TAS)}

Örneğin total antioksidan seviyesi, Rel Assay DiagnosticsTAS Assay Kit kullanılarak ölçüldü. Kit içerisindeki solüsyonlarla en güçlü biyolojik radikal olan hidrojen peroksit üretilerek numunenin antioksidatif etkisi belirlendi. Sonuçlar E vitamininin suda çözünür analogu olan Trolox ile kalibre edilerek $\mu \mathrm{mol}$ Trolox equiv./It olarak ifade edildi (Erel 2004). 


\section{DNA koruyucu aktivite}

Mantar özütünün, DNA'yı UV ve oksidatif kaynaklı hasarlardan koruma etkinliklerinin tespiti için pBR322 plazmid DNA kullanılmıştır. Plazmid DNA'sı, özütün varlığında $\mathrm{H}_{2} \mathrm{O}_{2}$ ve UV uygulanarak hasara uğratılarak (Russo ve ark. 2000) \% 1.25'lik agaroz jel üzerinde görüntüleme gerçekleştirilmiştir. Metanol özütlerinden

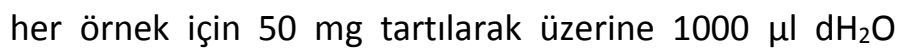
eklenip özütlerin tamamen çözünmesi sağlandıktan sonra seyreltme işlemi gerçekleştirilmiştir. \% 0.1'lik mantar özütü solüsyonundan $1 / 10$ oranında seyreltme yapılmıştır (Çizelge 1). Çalışma prosedüründe de bu plan kullanılmıştır (Tepe ve ark. 2011).

Çizelge 1 Kontrol ve mantar özütlerinin hazırlanması

\begin{tabular}{llllll}
\hline & Plazmit DNA & $\mathrm{dH}_{2} \mathrm{O}$ & $\mathrm{UV}$ & $\mathrm{H}_{2} \mathrm{O}_{2}$ & Örnek \\
\hline $\mathrm{K} 1$ (Kontrol) & $3 \mu \mathrm{l}$ & $6 \mu \mathrm{l}$ & - & - & - \\
$\mathrm{K} 2$ (Kontrol) & $3 \mu \mathrm{l}$ & $6 \mu \mathrm{l}$ & + & - & - \\
$\mathrm{K} 3$ (Kontrol) & $3 \mu \mathrm{l}$ & $6 \mu \mathrm{l}$ & + & $1 \mu \mathrm{l}$ & - \\
$\mathrm{K} 4$ (Kontrol) & $3 \mu \mathrm{l}$ & $6 \mu \mathrm{l}$ & - & $1 \mu \mathrm{l}$ & - \\
Özütler & $3 \mu \mathrm{l}$ & - & + & $1 \mu \mathrm{l}$ & $5 \mu \mathrm{l}$ \\
\hline
\end{tabular}

Kontrol dışında tüplere mantar özütünden $5.0 \mu \mathrm{l}$ konularak üzerine $3.0 \mu \mathrm{l}$ pBR322 plazmid DNA'sı (172

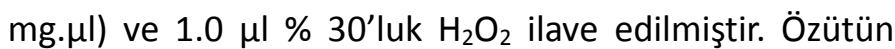
bulunduğu tüpler ile 2 . ve 3 . tüpler birlikte $5 \mathrm{dk}$ süresince UV ışınlarına maruz bıraktıktan sonra $2.0 \mu$ l yükleme tamponu eklenerek \% 1.25'lik agaroz jele yüklenmiştir. Işık kaynağı olarak oda sıcaklığında $302 \mathrm{~nm}$ dalga boyunda ve $8000 \mu \mathrm{W} / \mathrm{cm}$ yoğunlukta ışık üreten UV translüminatör (DNR-IS) cihazı kullanılmıştır. 100 dakika 100 voltluk \% 1.25'lik agaroz jel elektroforezi uygulamasından sonra jel dökümantasyon sisteminde (DNR-IS, MiniBIS Pro) görüntülenerek fotoğrafları çekilmiştir.

\section{Antimikrobiyal etki}

T. claveryi özütünün minimum inhibisyon konsantrasyonunun (MIK) belirlenebilmesi için elde edilen özütten $50 \mathrm{mg}$ alınarak $1 \mathrm{ml} \quad \mathrm{dH}_{2} \mathrm{O}$ de çözdürülmüştür. Ekstraktın antimikrobiyal aktivitesi Escherichia coli ATCC 25322, Staphylococcus aureus ATCC 25923, Pseudomonas aeruginosa DMS 50071, Salmonella typhi, Klebsiella pneumoniae ATCC 700603, Legionella pneumophila ATCC 33152, Trichophyton sp. ve Candida tropicalis ATCC 13803 suşları kullanılarak mikrodilüsyon yöntemiyle incelenmiştir. Elde edilen verilere göre ekstrakların MIK (Minimal Inhibisyon Konsantrasyonu) değerleri aşağıdaki verilere göre;

- $0,1 \mathrm{mg} / \mathrm{ml}$ 'den daha düşükse antimikrobiyal aktivite yüksek,

- $0,1 \mathrm{mg} / \mathrm{ml}-0,5 \mathrm{mg} / \mathrm{ml}$ arasındaysa, antimikrobiyal aktivite orta,

- $0,5 \mathrm{mg} / \mathrm{ml}-1 \mathrm{mg} / \mathrm{ml}$ arasında ise, antimikrobiyal aktivite zayıf,

- $1 \mathrm{mg} / \mathrm{ml}$ 'den fazla ise,

MIK değeri etkisiz olarak kabul edilmiştir (Morales ve ark. 2008).

\section{BULGULAR ve TARTIŞMA}

\section{Besinsel iç̧erikler ile ilgili çalışmalar}

Baskil - Elazığ çevresinden toplanan T. claveryi'de \%89.60 kuru madde, \%10.40 nem, \% 0.04 ham kül, \% 0.03 ham yağ, \%15.31 ham protein, \%83.47 organik madde, \%399.98 kcal enerji, $52.5 \mathrm{mg} / \mathrm{kg} \mathrm{K}, 560 \mathrm{mg} / \mathrm{kg} \mathrm{Na}, 0.58$ $\mathrm{mg} / \mathrm{kg} \mathrm{Ca}, 2.76 \mathrm{mg} / \mathrm{kg}$ Fe ve $0.37 \mathrm{mg} / \mathrm{kg} \mathrm{Zn}$ tespit edilmiştir (Çizelge 2). T. claveryi'nin ham besin madde içerikleri ile element düzeylerinin değişkenlik gösterdiği, besin içerikleri yönünden besleyici düzeyde olduğu ve element miktarlarının ise toksik düzeyde olmadıkları belirlenmiştir.

Çizelge 2 Baskil-Elazığ çevresinde yetişen T. claveryi'nin besinsel içeriği ve element düzeyleri

\begin{tabular}{|c|c|c|c|c|c|c|c|c|c|c|c|}
\hline \multicolumn{7}{|c|}{ Besinsel içerik (\%) } & \multicolumn{5}{|c|}{ Element } \\
\hline Kuru madde & Ham kül & Ham yağ & Ham protein & Organik madde & Enerji (kcal) & Nem & K & $\mathrm{Na}$ & $\mathrm{Ca}$ & $\mathrm{Fe}$ & $\mathrm{Zn}$ \\
\hline 89.60 & 0.04 & 0.03 & 15.31 & 83.47 & 399.98 & 10.40 & 52.5 & 560 & 0.58 & 2.76 & 0.37 \\
\hline
\end{tabular}


Farklı trüf türlerinde (T. boudieri, T. claveryi, T. olbiensis, T. nivea, T. pinoyi, P. lefebvrei) \%73.09-87.8 su, \%8.0235.87 protein, \%5.32-72.6 karbonhidrat, \%0.69-7.42 yağ, \%4.0-14.89 ham lif, \%0.59-15.29 ham kül ve element içeriklerinin ise ( $\mathrm{Ca}, \mathrm{Mg}, \mathrm{P}, \mathrm{Na}, \mathrm{K}, \mathrm{Fe}, \mathrm{Mn}, \mathrm{Cu}, \mathrm{Cd}, \mathrm{Cr}, \mathrm{Zn}$, $\mathrm{Pb}, \mathrm{Ni}, \mathrm{As} \mathrm{vb}$.) değişebildiği belirtilmiştir (Ahmed ve ark. 1981; Sawaya vd. 1985; Al-Naama ve ark. 1988; Bokhary ve Parvez 1993; Ibrahim ve Saeed 1994; Hashem ve AlObaid 1996; Hussain ve Al-Ruqaie 1999; Al-Ruqaie 2002; Dabbour ve Takruri 2002; Murcia ve ark. 2003; Al-Ruqaie 2006; Şahin 2012). T. claveryi'nin yapılan analizlerde $\% 83.14$ su, \%14.22 kül, \%32.27 protein, \%2.78 yağ, \%45.91 karbonhidrat, \%337.74 kcal enerji, $48.12 \mathrm{mg} / \mathrm{kg}$ $\mathrm{Na}, 998.4 \mathrm{mg} / \mathrm{kg} \mathrm{Mg}, 21.08 \mathrm{mg} / \mathrm{kg} \mathrm{Al}, 468.9 \mathrm{mg} / \mathrm{kg} \mathrm{P}$, $19337.3 \mathrm{mg} / \mathrm{kg} \mathrm{K}, 717.5 \mathrm{mg} / \mathrm{kg} \mathrm{Ca}, 2.01 \mathrm{mg} / \mathrm{kg} \mathrm{Cr}, 98.25$ $\mathrm{mg} / \mathrm{kg} \mathrm{Mn}, 27.19 \mathrm{mg} / \mathrm{kg} \mathrm{Fe}, 1.99 \mathrm{mg} / \mathrm{kg} \mathrm{Ni}, 29.42-29.48$ $\mathrm{mg} / \mathrm{kg} \mathrm{Cu}, 49.69 \mathrm{mg} / \mathrm{kg} \mathrm{Zn}, 0.98 \mathrm{mg} / \mathrm{kg} \mathrm{Cd}, 0.29 \mathrm{mg} / \mathrm{kg} \mathrm{Sn}$ ve $2.27 \mathrm{mg} / \mathrm{kg}$ Se içerdiği belirtilmiştir (Kıvrak 2015). Aynı türde \%84.21 su, \%14.35 kül, \%11.75 protein, \%1.35 yağ, \%72.55 karbonhidrat, \%349.35 kcal enerji ve element içerikleri bakımından ise $0.43 \mathrm{mg} / \mathrm{kg} \mathrm{Cr}, 55.0 \mathrm{mg} / \mathrm{kg} \mathrm{Mn}$, $101.0 \mathrm{mg} / \mathrm{kg} \mathrm{Fe}, 0.26 \mathrm{mg} / \mathrm{kg} \mathrm{Ni}, 3.22 \mathrm{mg} / \mathrm{kg} \mathrm{Cu}, 4.83$ $\mathrm{mg} / \mathrm{kg} \mathrm{Zn}, 0.02 \mathrm{mg} / \mathrm{kg}$ As, $0.07 \mathrm{mg} / \mathrm{kg} \mathrm{Cd}, 0.16 \mathrm{mg} / \mathrm{kg} \mathrm{Pb}$, $13.5 \mathrm{mg} / \mathrm{kg} \mathrm{Na}, 102.4 \mathrm{mg} / \mathrm{kg} \mathrm{Mg}, 788 \mathrm{mg} / \mathrm{kg} \mathrm{P}, 3854$ $\mathrm{mg} / \mathrm{kg} \mathrm{K}$ ve $6495 \mathrm{mg} / \mathrm{kg}$ Ca içerdiği tespit edilmiştir (Cansever 2014). T. boudieri'de \%89.75 kuru madde, \%10.25 su, \%7.80 ham kül, \%20.13 ham protein, \%3.45 ham yağ, \%81.95 organik madde, $63.8 \mathrm{mg} / \mathrm{g} \mathrm{K}, 0.27 \mathrm{mg} / \mathrm{g}$ $\mathrm{Ca}, 207.5 \mathrm{mg} / \mathrm{kg} \mathrm{Na}, 1455 \mathrm{mg} / \mathrm{kg} \mathrm{Fe}, 42.5 \mathrm{mg} / \mathrm{kg} \mathrm{Zn}, 15.8$ $\mathrm{mg} / \mathrm{kg} \mathrm{Mn}$ ve $30.1 \mathrm{mg} / \mathrm{kg}$ Cu saptanmıştır (Akyüz, 2013). T. olbiensis'de \%82.86 su, \%10.94 kül, \%15.79 protein, \%1.44 yağ, \%71.83 karbonhidrat, \%363.44 kcal enerji, $0.21 \mathrm{mg} / \mathrm{kg} \mathrm{Cr}, 17.5 \mathrm{mg} / \mathrm{kg} \mathrm{Mn}, 56.4 \mathrm{mg} / \mathrm{kg} \mathrm{Fe}, 0.08 \mathrm{mg} / \mathrm{kg}$ $\mathrm{Ni}, 4.02 \mathrm{mg} / \mathrm{kg} \mathrm{Cu}, 8.24 \mathrm{mg} / \mathrm{kg} \mathrm{Zn}, 0.02 \mathrm{mg} / \mathrm{kg} \mathrm{As}, 0.16$ $\mathrm{mg} / \mathrm{kg} \mathrm{Cd}, 0.11 \mathrm{mg} / \mathrm{kg} \mathrm{Pb}, 12.5 \mathrm{mg} / \mathrm{kg} \mathrm{Na}, 53.3 \mathrm{mg} / \mathrm{kg} \mathrm{Mg}$, $605 \mathrm{mg} / \mathrm{kg} \mathrm{P}, 3223 \mathrm{mg} / \mathrm{kg} \mathrm{K}, 319 \mathrm{mg} / \mathrm{kg}$ Ca saptanmıştır (Cansever, 2014).

$\mathrm{Bu}$ çalışmadaki sonuçlar ile diğer çalışmalardaki sonuçların benzer yada farklı çıkmasının temel nedenleri kullanılan mantar türüne, türün yetiştiği habitata, analizlerde kullanılan analitik yöntem ve cihazlara bağlı olarak değişebileceği söylenebilir. Bu bakımdan elde edilen sonuçlar literatürlerle uyum içindedir.

\section{Tıbbi Etkiler ile İlgili Çalışmalar}

T. claveryi'nin total antioksidan seviyesi $1.18 \mu \mathrm{mol} / \mathrm{l}$ ve total oksidan seviyesi $3.45 \mu \mathrm{mol} / \mathrm{l}$ olarak tespit edilmiştir (Çizelge 3). T. olbiensis, T. claveryi üzerine yapılan çalışmalarda farklı yöntemler kullanılarak etkin antioksidant etkiye ( $\beta$-carotene bleaching assay, DPPH, ABTS, antikolinesteras) sahip olduğu saptanmıştır (Kıvrak 2015). Bazı araştırıcılar tarafından Terfezia ve Picoa türleri üzerinde yapılan çalışmalarda TAS düzeyi 3.91-4.77 $\mu \mathrm{mol}$ TR/g (Murcia ve ark. 2002), 61.7- $0.5 \mu \mathrm{mol}$ TR/g (Özyürek ve ark. 2014), T. boudieri'de TAS $2.33 \mathrm{mmol} / \mathrm{L}$, TOS 26.95 $\mu \mathrm{mol} / \mathrm{L}$ ve OSI 1.156 (Sevindik ve ark. 2018) olarak değişkenlik göstermektedir. Çalışma sonucu bu verilerle kıyaslandığında $T$. claveryi'nin düşük antioksidan seviyesine sahip olduğu anlaşılmıştır.

Çizelge 3 T. claveryi'nin TAS ve TOS değerleri

\begin{tabular}{cc}
\hline TAS $(\mu \mathrm{mol} / \mathrm{I})$ & $\operatorname{TOS}(\mu \mathrm{mol} / \mathrm{I})$ \\
\hline 1.18 & 3.45 \\
\hline
\end{tabular}

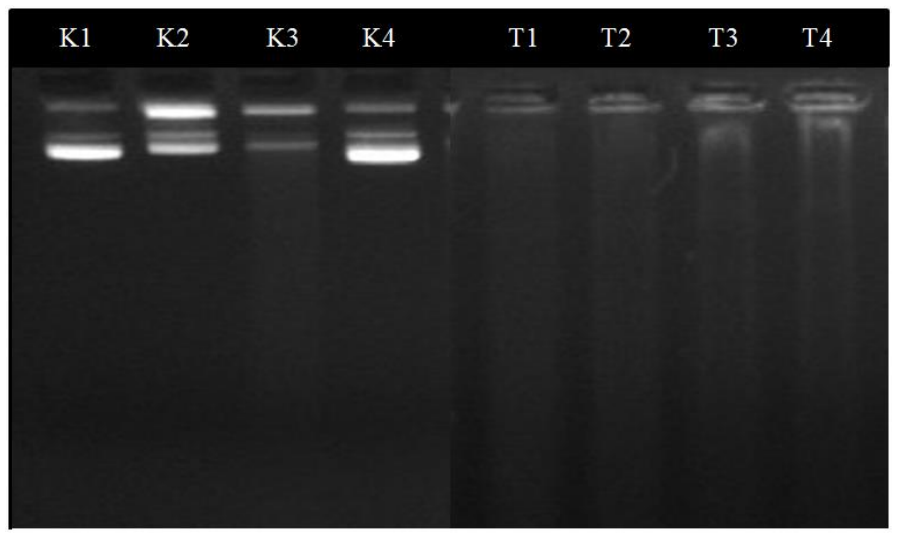

Şekil 1 T. claveryi'nin DNA koruyucu aktivitesi

K1: Kontrol: Plazmit DNA $(3 \mu \mathrm{l})+\mathrm{dH}_{2} \mathrm{O}(6 \mu \mathrm{l}) ; \mathrm{K} 2$ : Kontrol: Plazmit DNA $(3 \mu \mathrm{l})+\mathrm{dH}_{2} \mathrm{O}(6 \mu \mathrm{l})+\mathrm{UV}$; K3: Kontrol: Plazmit DNA $(3 \mu \mathrm{l})+\mathrm{dH}_{2} \mathrm{O}(6 \mu \mathrm{l})+\mathrm{UV}+\mathrm{H}_{2} \mathrm{O}_{2}(1 \mu \mathrm{l}) ; \mathrm{K} 4$ : Kontrol: Plazmit DNA $(3 \mu \mathrm{l})+\mathrm{dH}_{2} \mathrm{O}(6 \mu \mathrm{l})+\mathrm{H}_{2} \mathrm{O}_{2}(1 \mu \mathrm{l}) ; \mathrm{T} 1: 1 / 10$ oranında seyreltme için $5 \mathrm{ml}$ özüt+45 ml dH $2 \mathrm{O} ; \mathrm{T} 2: 1 / 5$ oranında seyreltme için $10 \mathrm{ml}$ özüt+40 ml dH ${ }_{2} \mathrm{O} ; \mathrm{T} 3: 1 / 2,5$ oranında seyreltme için $20 \mathrm{ml}$ özüt+30 ml dH $\mathrm{H}_{2} \mathrm{O}$; T4:

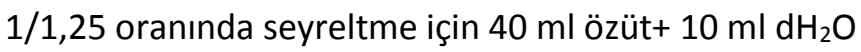

DNA üzerinde hasara yol açan UV ışınları ve $\mathrm{H}_{2} \mathrm{O}_{2}$ varlığında, mantar özütünün DNA hasarına engel olmadığı belirlenmiştir (Şekil 1). Ayrıca; mantarın DNA koruyucu aktivitesi pBR322 plazmit DNA'sı kullanılarak 
belirlenmeye çalışılmış ve DNA koruyucu aktivitesinin olmadığı tespit edilmiştir (Şekil 1).

T. claveryi için her bir mikroorganizmanın MIK değeri sırasılyla S.aureus $0.156 \mathrm{mg} / \mathrm{ml}, P$. aeruginosa 0.071 $\mathrm{mg} / \mathrm{ml}$, E. coli $0.156 \mathrm{mg} / \mathrm{ml}$, K. pneumoniae 0.312 $\mathrm{mg} / \mathrm{ml}$, S. thypi $0.312 \mathrm{mg} / \mathrm{ml}$, C. tropicalis $0.312 \mathrm{mg} / \mathrm{ml}$ ve Trichphyton sp. için $0.312 \mathrm{mg} / \mathrm{ml}$ olarak hesaplanmıştır. T. claveryi'nin antimikrobiyal çalışması sonucunda mikroorganizmaların düşük konsantrasyonlarda bile etki gösterdiği görülmüştür (Çizelge 4). Özellikle, P. aeruginosa'ya karşı en yüksek antimikrobiyal etki $(0.071 \mathrm{mg} / \mathrm{ml})$ gösterdiği belirlenmiştir (Çizelge 4). Bazı makrofunguslardan elde edilen ektraksiyonların (Agaricus, Pleurotus, Terfezia ve Picoa türleri) farklı patojen mikrrorganizmaları üzerine düşük düzeyde antimikrobiyal etki gösterdiği belirtilmiştir (Akyüz ve ark. 2010; Akyüz ve ark. 2015). Terfezia türlerinden elde edilen özütlerin $P$. aeruginosa için MIK değeri $166 \mathrm{mg} / \mathrm{ml}$ (Saddıq ve Daniel 2012), S. aureus için $0.025 \mathrm{mg} / \mathrm{ml}$ (Neggaz ve ark. 2015), S.aureus, E. coli, $P$. aeruginosa ve $K$. pneumonia için $0.40 \mathrm{mg} / \mathrm{ml}, 0.60 \mathrm{mg} / \mathrm{ml}$, $0.55 \mathrm{mg} / \mathrm{ml}$ ve $1.25 \mathrm{mg} / \mathrm{ml}$ (Aldebasi ve ark. 2013), S. aureus $<0.1 \mathrm{mg} / \mathrm{ml}$, P.aeruginosa $<0.1 \mathrm{mg} / \mathrm{ml}$, E.coli 0.1$0.5 \mathrm{mg} / \mathrm{ml}$, $K$. pneumoniae $<0.1 \mathrm{mg} / \mathrm{ml}$ olarak değişkenlik göstermektedir (Doğan ve ark. 2013). T. claveryi'nin antimikrobiyal aktiviteleri; kullanılan test yöntemi, mikrooganizma türlerine ve kullanılan kimyasal maddelere bağlı olarak değişebileceği vurgulanmıştır. Bu bakımdan elde ettiğimiz sonuçlar literatürlerle uyum içindedir.

Çizelge $4 T$. claveryi'in test mikroorganizmalarına karşı MIK değerleri (mg/ml)

\begin{tabular}{lcc}
\hline $\begin{array}{l}\text { Test } \\
\text { mikroorganizmaları }\end{array}$ & $\begin{array}{c}\text { Minimal inhibitör } \\
\text { konsantrasyonları }(\mathrm{mg} / \mathrm{ml})\end{array}$ & Kontrol \\
\hline S. aureus & 0.156 & 0.256 \\
E. coli & 0.156 & 0.256 \\
P. aeruginosa & 0.071 & 0.512 \\
S. thypi & 0.312 & 0.512 \\
K. pneumoniae & 0.312 & 0.256 \\
L. pneumophila & 5.000 & 20.000 \\
C. tropicalis & 0.312 & 0.512 \\
Trichophyton sp. & 0.312 & 0.512 \\
\hline
\end{tabular}

Sonuç olarak, $T$. claveryi'nin besin içerikleri yönünden zengin olduğu ve element düzeylerinin ise toksik düzeylerde olmadığı saptanmıştır. Ayrıca, tıbbi etkiler bakımından ise değerli besin kaynakları olduğu tespit edilmiştir. Ülkemizde doğal olarak yetişen ve besin olarak tüketilen $T$. claveryi üzerine daha ayrıntılı çalışmaların yapılması gerektiği tespit edilmiştir.

\section{KAYNAKLAR}

Ahmed A, Mohammed M, Hami M (1981) Libyan truffles Terfezia boudieri Chatin chemical composition and toxicity. J Food Sci 46: 927-929.

Akyüz M, Onganer AN, Erecevit P, Kirbag S (2010) Antimicrobial activity of some edible mushrooms in the eastern and southeast Anatolia region of Turkey. Gazi Univ J Sci 23: 125-130.

Akyüz M, Kırbağ S, Bircan B, Gürhan Y (2015a) Diversity and distribution of arid-semi arid truffle (Terfezia and Picoa) in ElazığMalatya region of Turkey. Mycosphere 6:766-783.

Akyüz M, Kırbağ S, Bircan B (2015b) Medical characteristics of aridsemi arid truffle (Terfezia and Picoa) in the Elazığ-Malatya region of Turkey. Hacettepe J Biol Chem 43: 301-08.

Akyüz M (2013) Nutritive value, flavonoid content and radical scavenging activity of the truffle (Terfezia boudieri Chatin). J Soil Sci Plant Nutr 13: 143-151.

Akyüz M, Kırbağ S, Gürhan Y, Bircan B (2016) Determination of mycorrhizal relations, and ex situ and in situ conservation of Terfezia and Picoa truffles that grow naturally in the Elazığ-Malatya Region of Turkey. Artvin Coruh Univ Orman Fak Derg 17: 1-10.

Akyüz M, Kirbağ S, Kurşat M (2012) Ecological aspects of the arid and semi-arid truffle in Turkey: evaluation of soil characteristics, morphology, distribution, and mycorrhizal relationships. Turk J Bot 36: 386-391.

Aldebasi YH, Aly SM, Qureshi MA, Khadri H (2013) Novel antibacterial activity of Terfezia claveryi aqueous extract against clinical isolates of corneal ulcer. Afr J Biotech 12: 6340-6346.

Al-Naama NM, Ewaze JO, Nema JH (1988) Chemical constituents of Iraqi truffles. Iraqi J Agric Sci 6: 51-56.

Al-Ruqaie IM (2002) Effect of different treatment processes and preservation methods on the quality of truffles. I. Conventional methods (drying/freezing). Pak J Biol Sci 5: 1088-1093.

Al-Ruqaie IM (2006) Effect of different treatment processes and preservation methods on the quality of truffles: I. Conventional methods (drying/freezing). J Food Proces Preservation, 30, 335351.

AOAC (1990) Official methods of analysis of association of the official analytical chemists. Eds.: Helrich K. Published by the Association of Official Analytical Chemists Inc. Wilson Boulevard Arlington, Virginia 22201 USA; Fifteenth Edition, p. 1213.

Aydın S (2009) Terfezia boudieri Chatin ve Lactarius vellereus (Fr.) Fr.'un antioksidan, antimikrobiyal etkilerinin ve yağ asidi kompozisyonunun belirlenmesi. Doktora Tezi, Selçuk Üniversitesi Fen Bilimleri Enstitüsü, Konya-Türkiye.

Bekçi H, Altinsoy B, Sarikaya S, Onbasili D, Çelik GY (2011) Kastamonu yöresinden toplanan bazı makrofungusların antimikrobiyal aktivitesi. Kastamonu Üniv Orman Fak Derg 11: 187-190.

Bokhary HA, Parvez S (1993) Chemical composition of desert truffles Terfezia claveryi. J Food Comp Anal 6: 285-293.

Breene WM (1990) Nutritional and medicinal value of speciality mushrooms. J Food Protection 53: 883-894.

Cansever Ti (2014) Terfezia olbiensis ve Terfezia claveryi mantarlarının kimyasal bileşenleri ve besinsel özelliklerinin araştırılması. Yüksek Lisans Tezi, Muğla Sıtkı Koçman Üniversitesi Fen Bilimleri Enstitüsü, Muğla, Türkiye. 
Castellano MA, Türkoğlu A (2012) New records of truffle taxa in Tuber and Terfezia from Turkey. Turk J Bot 36: 295-298.

Dabbour IR, Takruri HR (2002) Protein quality of four types of edible mushrooms found in Jordan. Plant Foods Hum Nutr 57: 1-11.

Doğan HH, Kurt F (2016) New macrofungi records from Turkey and macrofungal diversity of Pozanti-Adana. Turk J Bot 40: 209-217.

Doğan HH, Duman R, Özkalp B, Aydin S (2013) Antimicrobial activities of some mushrooms in Turkey. Pharmaceut Biol 51: 707-711.

Elliott TF, Türkoğlu A, Trappe JM, Güngör MY (2016) Turkish truffles 2: eight new records from Anatolia. Mycotaxon 131: 439-453.

Erel O (2004) A novel automated direct measurement method for total antioxidant capacity using a new generation, more stable ABTS radical cation. Clin Biochem 37: 277-285.

Erel O (2005) A new automated colorimetric method for measuring total oxidant status. Clin Biochem 38: 1103-1111.

Gunde-Cimerman N (1999) Medicinal Value of the Genus Pleurotus (Fr.) P. Karst. (Agaricales S.I, Basidiomycetes). Inter J Med Mushroom 1: 69-80.

Gutiérrez A, Morte A, Honrubia M (2003) Morphological characterization of the mycorrhiza formed by Helianthemum almeriense Pau with Terfezia claveryi Chatin and Picoa lefebvrei (Pat.) Maire. Mycorrhiza 13: 299-307.

Hashem AR, Al-Obaid AM (1996) Mineral composition of soil and wild desert truffies in Saudi Arabia. J King Saud Univ 8: 5-10.

Hussain G, Al-Ruqaie IM (1999) Occurrence, chemical composition, and nutritional value of truffles: an overview. Pak J Biol Sci 2: 510514.

Ibrahim NA, Saeed AA (1994) Protein content and amino acid analysis of the desert truffles. Ann Agr Sci Moshtohor 32: 1569-1573.

Kagan-Zur V, Roth Bejerano N, Sitrit Y, Morte A (2014) Desert truffle (phylogeny, physiology, distribution and domestication). Springer Verlag Berlin Heidelberg.

Kıvrak i (2015) Analytical methods applied to assess chemical composition, nutritional value and in vitro bioactivities of Terfezia olbiensis and Terfezia claveryi from Turkey. Food Anal Methods 8: 1279-1293.

Loizides M, Hobart C, Konstandinides G, Yiangou Y (2012) Desert truffles: the mysterious jewels of antiquity. Field Mycol, 17-21.

Mattila P, Suonpaa K, PiironenV (2000) Functional properties of edible mushrooms. Nutrition 16: 694-696.

Misaki A, Kakuta M (1995) Kikurage (Tree-ear) and Shirokikurage (White jellyleaf): Auricularia auricula-judae and Tremella fuciformis. Food Rev Inter 11: 211- 218.
Morales G, Paredes A, Sierra P, Loyola LA (2008) Antimicrobial activity of three Baccharis species used in the traditional medicine of northern Chile. Molecules 13:790-794.

Murcia MA, Martınez-Tome M, Jimenez AM, Vera AM, Honrubia $M$, Parras P (2002) Antioxidant activity of edible fungi (truffles and mushrooms): Losses during industrial processing. J Food Protect 65: 1614-1622.

Murcia, MA, Martınez-Tome M, Vera A, Morte A, Gutierrez A, Honrubia M (2003) Effect of industrial processing on desert truffles Terfezia claveryi Chatin and Picoa juniperi Vittadini: Proximate composition and fatty acids. J Sci Food Agric 83: 535-541.

Neggaz S, Fortas Z, Chenni M, El Abed, D, Ramli B, Kambouche N (2015) In vitro evaluation of antioxidant, antibacterial and antifungal activities of Terfezia claveryi Chatin. Phytothérapie 1-7.

Özyürek M, Bener M, Güçlü K, Apak R (2014) Antioxidant/antiradical properties of microwave-assisted extracts of three wild edible mushrooms. Food Chem 157: 323-331.

Russo A, Acquaviva R, Campisi A, Sorrenti V, DiGiacomo C, Virgata G, Barcellona ML, Vanella A (2000) Bioflavonoids as antiradicals, antioxidantsand DNA cleavage protectors. Cell Biol Toxicol 16: 9198.

Saddıq AA, Danial EN (2012) Assessment of phenolic content, free radical-scavenging capacity and antimicrobial activities of Truffle clavery. Wulfenia J 19: 403-422.

Sanmee R, Dell B, Lumyong P, Izumori K, Lumyong S (2003) Nutritive value of popular wild edible mushrooms from Northern Thailand. Food Chem 82: 527-532.

Sawaya WN, Al-Shalhat A, Al-Sogair A, Mohammad M (1985) Chemical composition and nutritive value of truffles of Saudi Arabia. J Food Sci 50: 450-453.

Sevindik M, Pehlivan M, Dogan, M, Selamoglu Z (2018) Phenolic content and antioxidant potential of Terfezia boudieri. Gazi Univ J Sci 31: 707-711.

Şahin A (2012) Konya yöresinde yetişen Terfezia türleri ve etnomikolojik özellikleri, Yüksek Lisans Tezi, Selçuk Üniversitesi Fen Bilimleri Enstitüsü, Konya, Türkiye.

Tepe B, Degerli S, Arslan S, Malatyali E, Sarikurkcu C (2011) Determination of chemical profile, antioxidant, dna damage protection and antiamobic activities of Teucrium polium and Stachy siberica. Fitoterapia 82: 237-246.

Türkoğlu A, Castellano MA (2014) New records of some Ascomycete truffle fungi from Turkey. Turk J Bot 38: 406-416.

Türkoğlu A, Castellano M, Trappe JM, Güngör MY (2015) Turkish truffles I: 18 new records for Turkey. Turk J Bot 39: 359-376. 